Journal of Patient-Centered

\title{
Understanding and Using Patient Experience Feedback to Improve Health Care Quality: Systematic Review and Framework Development
}

\author{
Emmanuel Kumah \\ Felix Osei-Kesse \\ Cynthia Anaba
}

Follow this and additional works at: https://aah.org/jpcrr

Part of the Health and Medical Administration Commons, and the Health Services Research Commons

\section{Recommended Citation}

Kumah E, Osei-Kesse F, Anaba C. Understanding and using patient experience feedback to improve health care quality: systematic review and framework development. J Patient Cent Res Rev. 2017;4:24-31. doi: 10.17294/2330-0698.1416

Published quarterly by Midwest-based health system Advocate Aurora Health and indexed in PubMed Central, the Journal of Patient-Centered Research and Reviews (JPCRR) is an open access, peer-reviewed medical journal focused on disseminating scholarly works devoted to improving patient-centered care practices, health outcomes, and the patient experience. 


\title{
Understanding and Using Patient Experience Feedback to Improve Health Care Quality: Systematic Review and Framework Development
}

\author{
Emmanuel Kumah, MSc, BSc, ${ }^{1}$ Felix Osei-Kesse, MBA, BSc, ${ }^{2}$ Cynthia Anaba, MSc, BSc ${ }^{3}$ \\ ${ }^{1}$ Institute of Management, Scuola Superiore Sant Anna, Pisa, Italy \\ ${ }^{2}$ Department of Administration, Prestia Government Hospital, Prestia, Western Region, Ghana \\ ${ }^{3}$ Department of Administration, St. Dominic Hospital, Akwatia, Eastern Region, Ghana
}

\begin{abstract}
Patient experience data is increasingly collected worldwide; however, questions persist regarding how it is used to improve health care quality. Synthesizing information from the existing literature, we have developed an empirically based framework to help organizations and managers understand what to do with patient experience feedback to improve health care quality at the organizational level. We identified six post-data collection/analysis activities, which were categorized into three main themes: 1) make sense of the data, 2) communicate and explain the data, and 3) plan for improvement. Our framework suggests that simply executing a survey will not improve performance. It is necessary that leaders understand the data, disseminate findings to all stakeholders, help staff understand the data, and then create a platform where all key stakeholders can be involved in discussing the results to generate improvement plans. (J Patient Cent Res Rev. 2017;4:24-31.)
\end{abstract}

Keywords patient experience; patient feedback; quality improvement; quality of care; organizational level

Patient feedback surveys are increasingly seen as a key component of health care quality monitoring and improvement. ${ }^{1}$ In recent years, there has been a trend away from global satisfaction measures to a more detailed measurement of the patient experience. Patient experience is a measure of patient-centeredness, one of the U.S. Institute of Medicine's proposed six health care quality aims. ${ }^{2}$ It is made up of the relational (interpersonal) and functional (expectations about how care is delivered) aspects of care. ${ }^{3}$

Many countries are using patient experience data to measure health care quality. In countries such as the United Kingdom, United States, Australia, Canada, New Zealand and many European countries, systematic arrangements have been made for patient experience to be measured and monitored at the national level. ${ }^{4}$ The World Health Organization uses measures of

Correspondence: Emmanuel Kumah, MSc, BSc, Institute of Management, Scuola Superiore Sant Anna,

Piazza Martiri della Libertà, 33, Pisa, PI, Italy,

T: +393319947428, Email: ababiohemmanuel@gmail.com patient experience as an indicator of a health system's responsiveness. The responsiveness of a system is reflected by an overall improvement in the health status of the people served, ensuring equity and efficiency while protecting individuals from unreasonable costs. ${ }^{5}$

At the organizational level, a common feature regarding the purpose of patient-reported experiences is quality improvement. ${ }^{6}$ Earlier studies have demonstrated that systematic gathering of patient feedback by hospitals may result in small to moderate improvements. ${ }^{7-9}$ However, despite data on patient experience being increasingly collected worldwide, there are still questions regarding how it is used to improve health care quality. ${ }^{10,11}$ Little effort has gone into how to understand and use patient experience data to increase the responsiveness of a health care organization to the needs of its clients. ${ }^{11,12}$

For this paper, we synthesized findings from the existing literature to develop a framework for understanding what to do with patient experience feedback to improve health care quality at the organizational level. Our framework outlines post-data collection and analysis activities - in 
short, how survey results can be understood, organized, reported and fed into service improvement activities. By generating an empirically based framework for optimizing organizational strategies, resources and practices in using patient experience data, we believe this study will contribute to the knowledge base for improving patient experiences and health care quality.

\section{Identification of Studies}

We conducted a comprehensive search to identify studies using combinations and variants of the following key terms: "patient experience data," "patient satisfaction data," "patient feedback results," "quality improvement," "quality assurance," and "quality of care." English-language articles published in peerreviewed journals from January 2000 to March 2016 were searched in the following electronic databases: PubMed, Web of Science, Scopus and Cochrane Library. As an example, the search strategy developed for PubMed is presented in Online Appendix 1. Additional studies were obtained through manual search and from the reference lists of included studies.

\section{Study Selection and Abstraction}

To be considered for inclusion, an article had to address issues related to patient experience or satisfaction and discuss at least one activity carried out in translating patient feedback data into quality improvement initiatives. Titles and abstracts were first screened to exclude reports that were irrelevant to the topic. Full texts of the articles selected after the initial screening were retrieved and independently read by two authors to check whether or not they fulfilled the inclusion criteria. Disagreements were resolved by discussion with a third member of the research team. Relevant information was abstracted from the results and discussion sections of papers into a spreadsheet. Two reviewers reviewed the spreadsheet independently and categorized the information to identify emerging themes. The study team continued discussing and refining the themes until a consensual understanding was reached.

\section{Characteristics of Included Articles}

A flow chart of the study selection process is shown in Figure 1. A total of 738 records were identified from

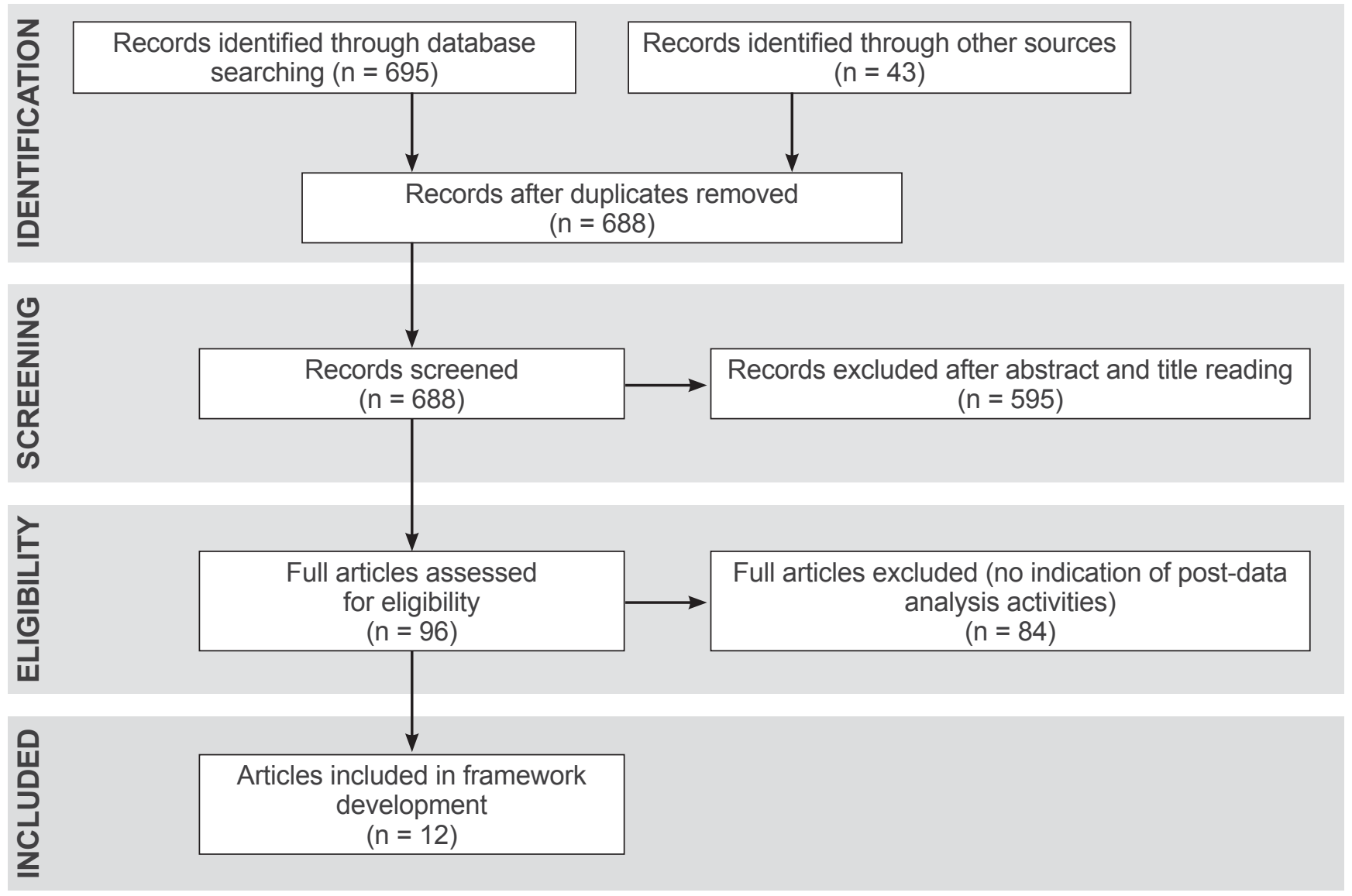

Figure 1. Flow diagram of literature search. 
the literature search. After removing duplicates, 688 records remained. We retained 96 full texts for further assessment following title and abstract review. After examining the full texts, 84 articles were excluded for lack of information on how patient feedback results were used. We used information from 12 studies to develop the framework. Approximately $42 \%(n=5)$ of the studies were conducted in the United States, while the remaining 58\% $(\mathrm{n}=7)$ were carried out in Europe. Publication dates of the 12 papers ranged from 2003 to 2013 (Table $1^{13-24}$ ).

\section{Post-Data Collection and Analysis Activities}

Our comprehensive analysis evolved into six post-data collection/analysis activities; details are displayed in Table 2. The six activities are:

- Benchmarking: Two studies ${ }^{13,14}$ reported that survey findings were examined against results of other organizations and agencies.

- Comparison of Findings With Historical Data: Two studies ${ }^{13,14}$ indicated that organizations compared results with prior survey findings and examined trends.

Table 1. Characteristics of Selected Articles $(\mathrm{N}=12)$

\begin{tabular}{|c|c|c|c|c|}
\hline Study & Aim/objective & Sample & Design/method & Country of study \\
\hline Boyer et al. ${ }^{15}$ & $\begin{array}{l}\text { Assess clinical staff's opinions on the } \\
\text { results of inpatient surveys and their } \\
\text { use within QI process }\end{array}$ & 261 clinicians & $\begin{array}{l}\text { Questionnaire } \\
\text { survey }\end{array}$ & France \\
\hline Davies et al. ${ }^{16}$ & $\begin{array}{l}\text { Assess promoters and barriers to care } \\
\text { improvement efforts }\end{array}$ & $\begin{array}{l}8 \text { respondents of } \\
\text { two facilities }\end{array}$ & Case study & U.S. \\
\hline Reeves et al. ${ }^{18}$ & $\begin{array}{l}\text { Test the feasibility of conducting ward } \\
\text { level surveys, providing ward level data } \\
\text { and conducting meetings }\end{array}$ & 4,236 patients & Postal survey & England \\
\hline Davies and Cleary ${ }^{19}$ & $\begin{array}{l}\text { Develop a framework for understanding } \\
\text { factors affecting the use of patient } \\
\text { survey data in QI }\end{array}$ & $\begin{array}{l}14 \text { medical team } \\
\text { leaders and } \\
\text { members }\end{array}$ & $\begin{array}{l}\text { Qualitative } \\
\text { interview with } \\
\text { literature review }\end{array}$ & U.S. \\
\hline Wensing et al. ${ }^{24}$ & $\begin{array}{l}\text { Examine responses of GPs to patients' } \\
\text { feedback }\end{array}$ & 52 GPs & $\begin{array}{l}\text { Cluster } \\
\text { randomized trial }\end{array}$ & Netherlands \\
\hline Iversen et al. ${ }^{20}$ & $\begin{array}{l}\text { Address employees' attitudes and use } \\
\text { of national patient experience survey } \\
\text { results }\end{array}$ & 79 employees & $\begin{array}{l}\text { Electronic } \\
\text { questionnaire } \\
\text { survey }\end{array}$ & Norway \\
\hline Fierdberg et al. ${ }^{21}$ & $\begin{array}{l}\text { Examine whether and how physician } \\
\text { groups are using patient experience } \\
\text { data to improve patient care }\end{array}$ & $\begin{array}{l}72 \text { physician } \\
\text { group leaders }\end{array}$ & $\begin{array}{l}\text { Qualitative } \\
\text { (semi-structured } \\
\text { interview) }\end{array}$ & U.S. \\
\hline Koch et al. ${ }^{13}$ & $\begin{array}{l}\text { Understand the use of data from an } \\
\text { annual survey of behavioral health } \\
\text { consumers }\end{array}$ & 77 participants & $\begin{array}{l}\text { Cross-sectional } \\
\text { survey, follow-up } \\
\text { interviews }\end{array}$ & U.S. \\
\hline Heje et al. ${ }^{22}$ & $\begin{array}{l}\text { Study the impact of patient evaluation } \\
\text { and subsequent feedback results on } \\
\text { physicians as well as facilitators and } \\
\text { barriers to the implementation of results } \\
\text { raised by patient evaluation processes }\end{array}$ & 474 GPs & Survey & Denmark \\
\hline Zuidgeest et al. ${ }^{23}$ & $\begin{array}{l}\text { Examine the usability of the Consumer } \\
\text { Quality Index questionnaires used in } \\
\text { nursing homes and homes for the } \\
\text { elderly in quality improvement }\end{array}$ & 47 employees & $\begin{array}{l}\text { Qualitative (face- } \\
\text { to-face) interview }\end{array}$ & Netherlands \\
\hline Davies et al. ${ }^{17}$ & $\begin{array}{l}\text { Evaluate the use of a modified } \\
\text { Consumer Assessment of Health } \\
\text { Providers and Systems survey to } \\
\text { support quality improvement }\end{array}$ & & $\begin{array}{l}\text { Process } \\
\text { evaluation }\end{array}$ & U.S. \\
\hline $\begin{array}{l}\text { Reeves and } \\
\text { Seccombe }\end{array}$ & $\begin{array}{l}\text { Assess attitudes toward national patient } \\
\text { survey programs, establish the extent } \\
\text { of usage of results, and identify barriers } \\
\text { and incentives }\end{array}$ & $\begin{array}{l}24 \text { patient survey } \\
\text { leads for NHS } \\
\text { trusts }\end{array}$ & $\begin{array}{l}\text { Qualitative } \\
\text { interview }\end{array}$ & England \\
\hline
\end{tabular}

GP, general practitioner; NHS, National Health Service; QI, quality improvement. 
- Follow-Up Data: Four studies ${ }^{14-17}$ indicated that additional data were gathered to further understand patient perspectives. Tools used included: complementary surveys, ${ }^{15}$ active conversations with patients, ${ }^{16}$ walkthroughs, patient interviews, patient focus groups and cycle-time surveys. ${ }^{17}$
- Dissemination of Findings: Eleven studies ${ }^{13-23}$ reported that results were communicated internally. For instance, Boyer et al. ${ }^{15}$ indicated that the study hospital communicated overall results to both medical and nonmedical staff, while specific results were sent to the wards/departments concerned. In addition to

Table 2. Post-Data Collection and Analysis Activities

\begin{tabular}{|c|c|}
\hline Study & Post-data collection/analysis activities \\
\hline Boyer et al. ${ }^{15}$ & $\begin{array}{l}\text { - Overall hospital results are sent to all the medical and nonmedical staff; specific results are sent to the } \\
\text { wards/departments concerned } \\
\text { - A complementary survey is conducted to clarify issues raised by patients } \\
\text { - Results are discussed within departments during staff meetings } \\
\text { - Action is taken to solve problems }\end{array}$ \\
\hline Davies et al. ${ }^{16}$ & $\begin{array}{l}\text { - Employ performance improvement coordinator to disseminate and explain the results to the } \\
\text { management group of each clinical unit } \\
\text { - Supervising physicians and nursing managers explain results to frontline staff to understand and } \\
\text { encourage their involvement in finding solutions } \\
\text { - Collect additional data to further understand patients' perspectives }\end{array}$ \\
\hline Reeves et al. ${ }^{18}$ & $\begin{array}{l}\text { - Disseminate results } \\
\text { - Hold ward meetings to discuss results and offer suggestions for improvement }\end{array}$ \\
\hline Davies and Cleary ${ }^{19}$ & $\begin{array}{l}\text { - Review survey results at the board } \\
\text { - Use patients' complaints to identify areas for improvement } \\
\text { - Feed survey data back to individual clinicians }\end{array}$ \\
\hline Wensing et al. ${ }^{24}$ & $\begin{array}{l}\text { - Discuss results with colleagues } \\
\text { - Participate in continuing education } \\
\text { - Change practice routines or change the organization of the practice }\end{array}$ \\
\hline Iversen et al. ${ }^{20}$ & $\begin{array}{l}\text { - Communicate results to departments } \\
\text { - Formal (departmental meetings) and informal discussions } \\
\text { - Implement changes }\end{array}$ \\
\hline Fierdberg et al. ${ }^{21}$ & - Share best practices within physician groups \\
\hline Koch et al. ${ }^{13}$ & $\begin{array}{l}\text { - Share results throughout the organization and to consumers and stakeholders } \\
\text { - Compare results with those of other organizations and examine trends } \\
\text { - Train staff on how to interpret/use results }\end{array}$ \\
\hline Heje et al. ${ }^{22}$ & $\begin{array}{l}\text { - Feed results back to general practitioners } \\
\text { - Feedback meetings held and general practitioners are guided through the interpretation of the results } \\
\text { (tables and figures); staff involved in using data }\end{array}$ \\
\hline Zuidgeest et al..$^{23}$ & $\begin{array}{l}\text { - Disseminate results throughout the organization } \\
\text { - Project groups point out quality improvement initiatives and every worker is involved in the processes } \\
\text { - Publish results and ratings on the Internet }\end{array}$ \\
\hline Davies et al. ${ }^{17}$ & $\begin{array}{l}\text { - Present results at staff meetings to generate action plans } \\
\text { - Assess reasons for survey results (walkthroughs, patient interviews, patient focus groups, cycle- } \\
\text { time surveys) }\end{array}$ \\
\hline $\begin{array}{l}\text { Reeves and } \\
\text { Seccombe }\end{array}$ & $\begin{array}{l}\text { - Disseminate results to staff through the organization's intranet, newsletters and meetings } \\
\text { - Communicate results to patients and the public through posters and leaflets in public areas, press } \\
\text { releases and reports } \\
\text { - Present summary reports to the hospital board } \\
\text { - Compare results with previous performance and that of other hospitals } \\
\text { - Supplement results with complaints from patients and information from the patient advice and liaison } \\
\text { services } \\
\text { - Hold teaching sessions and special events to engage staff in forward planning }\end{array}$ \\
\hline
\end{tabular}


internal communication, three studies ${ }^{13,14,23}$ indicated that organizations communicated the results to patients and the general public through posters and leaflets, press releases, reports and online publications.

- Teaching and Interpreting Results: Four studies ${ }^{13,14,16,22}$ stated that teaching and interpretation activities helped staff understand the data collected. For example, Davies and colleagues reported that performance improvement coordinators were employed to explain the results to the management of each clinical unit. Supervising physicians and nursing managers were engaged to interpret the findings to frontline staff. ${ }^{16}$ Koch et al. ${ }^{13}$ also indicated that training sessions were held for staff on how to interpret and use the data gathered.

- Discussion of Findings and Planning for Improvement: Discussion of feedback findings was found in five studies. ${ }^{13,15,18,20,24}$ This was mostly done at departmental, staff or ward meetings ${ }^{15}$ and through informal discussions. ${ }^{20}$ The aims of these discussions were to solicit input/suggestions from staff, ${ }^{18}$ set priorities ${ }^{16}$ and generate action plans for care improvement. ${ }^{15,17}$

\section{Framework Development}

We categorized the six post-data collection/analysis activities into three main themes: "make sense of the data," "communicate and explain data," and "plan for improvement" (Figure 2). The main focus of our framework centers on the following question: You have the data and you have heard all the voices, but how do you work with it properly to improve the quality of care? Areas outside the scope of the framework include: how to conduct patient experience or feedback surveys, and how to implement quality improvement initiatives. These topics have been addressed extensively in the literature.

Make Sense of Data: Before the leaders of an organization can explain, interpret and use patient experience data effectively in quality improvement efforts, they must first understand the information collected. One way to understand patient experience data is to undertake a comparative data analysis. This includes comparing the data with prior information, ${ }^{13,14}$ comparing findings with the results of similar organizations (external benchmarking), ${ }^{13,14}$ and comparing results within the organization in terms of departments, wards and units (internal benchmarking). Comparative data analysis helps to determine performance trends, identify where an organization's performance is stronger or weaker and ascertain whether certain departments or units are performing better than others. ${ }^{13}$ Another way to understand patient experience survey results is to complement the data with qualitative feedback through focus groups or patient interviews. This helps in clarifying and understanding concerns raised by patients. ${ }^{15-17}$

Communicate and Explain Data: This theme encompasses two activities — sharing survey feedback with key stakeholders (staff, patients, general public) ${ }^{13-23}$ and explaining the collective data to the specific staff who will act on it to improve care quality. ${ }^{13,14,16,22}$ In one of the selected articles, ${ }^{14}$ results were first communicated to stakeholders through meetings, newsletters, press releases, posters, reports

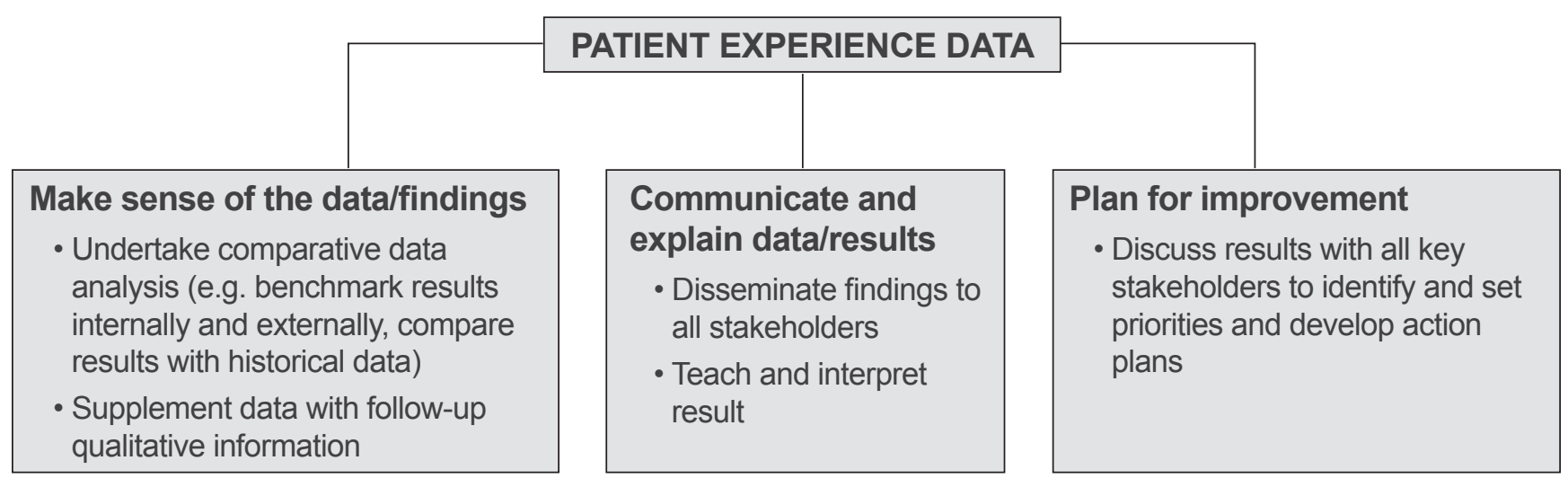

Figure 2. A framework for understanding and using patient experience data to improve health care quality. 
and formal presentations. Teaching sessions were then held to train staff on how to interpret/use the data. This resulted in active stakeholder participation in developing and implementing quality improvement plans to improve users' care experiences.

Plan for Improvement: Having disseminated and interpreted the results of the survey, organizations then need to decide what to do with the information and where to focus improvement efforts. This stage requires working in partnership with patients, service users and staff at every level of the organization. ${ }^{15}$ Analyzed studies indicated that organizations involved stakeholders in: discussing survey results, ${ }^{15,18,20,24}$ setting priorities and deciding appropriate courses of action, and developing action plans for service improvement. ${ }^{15,17}$ These activities helped the organizations implement effective patient-centered quality improvement plans. ${ }^{18}$

\section{Discussion}

From routine surveys and a body of quantitative and qualitative research, we know the aspects of care that patients and care users consider important. ${ }^{12}$ We also know factors that influence patients' and families' care experiences. ${ }^{25}$ What is less known is how organizations understand and use patient experience data to improve the quality of health care. ${ }^{11,12,14}$ Therefore, we used information from the extant literature to develop a framework that could help organizations and health care managers use such data more effectively to improve patient experiences and health care quality.

Our framework suggests that simply carrying out a survey will not improve performance. It is important that leaders understand the data, disseminate these findings to all stakeholders, help staff understand the data and then create a platform in which all key stakeholders can be involved in discussing the results to generate improvement plans.

Most patient feedback data is quantitative in nature. ${ }^{20}$ To provide a more comprehensive picture and in-depth understanding of patient and caregiver experiences, it is useful to supplement this information with qualitative data. ${ }^{23}$ Qualitative information can be gathered in two ways - by conducting a complementary qualitative study, as indicated by several publications, ${ }^{14-17}$ or by including open-ended questions in survey questionnaires. ${ }^{20} \mathrm{By}$ including qualitative information, organizations can better and more fully understand patients' concerns and generate appropriate action plans to improve user experiences.

Even though none of the selected studies indicated that survey results were compared internally, we believe that internal comparison of results may enable organizations to better understand patient experience data. For instance, if the organization is performing better in some departments than others, it may be possible to identify the reasons for this performance variation through internal benchmarking of results.

Although reporting of patient experience feedback has the potential to improve health care quality, it is important for organizational leaders to help staff understand the complex nature of the data collected. ${ }^{19}$ Difficulty surrounding the understanding and interpretation of patient feedback data by staff has been well acknowledged in the literature..$^{11,26,27}$ Rather than simply sending out tables and figures and assuming that staff will interpret them properly, health care managers need to follow dissemination of feedback findings with effective educational programs. ${ }^{28}$ Optimal use of patient experience data also requires that health care managers understand potential barriers to the use of such information. Previous studies have demonstrated that factors such as insufficient time to discuss survey results, lack of resources for educational programs, delays in disseminating results, clinicians' lack of interest in the data, inadequate quality improvement staffing to fully exploit the data and employee resistance to change can hamper the optimal use of patient experience data in quality improvement efforts. ${ }^{14,16,30}$ Anticipating and understanding these potential barriers may help managers plan to minimize them.

Involving patients and service users in planning for improvement is essential for success. Based on our framework, patients should be recognized as more than providers of data for professionals and organizations. Their views should be incorporated when acting on the information they provide. The recent literature emphasizes the use of quality improvement methodologies that involve patients and service users as part of "co-design." 29 However, it appears that this 
practice is not very common at the organizational level. ${ }^{13}$ Thus, policy makers need to do more to encourage organizations to involve service users in their quality improvement programs.

\section{Study Limitations}

Our methodology has some limitations. First, we restricted our review to only English-language articles, thereby posing the risk of publication bias. This might have limited our findings. Also, selected studies were conducted in Europe and the United States. This may limit the applicability of our framework to other parts of the world.

\section{Conclusions}

A comprehensive review of the literature confirmed that little empirical evidence exists regarding how patient experience data is used to drive quality improvement in organizations and clinical services. Only 12 studies reported on at least one activity describing how patient feedback results were used. It has been argued that health care organizations focus on collecting data rather than using the information to improve service quality. ${ }^{4}$ More empirical work is required to determine the means and extent that organizations are using patient experience survey data for service improvement. The framework presented in this review could provide a conceptual basis for more effective use of patient experience feedback.

\section{Patient-Friendly Recap}

- Many health care systems use surveys to collect information on the patient experience.

- How to use this patient feedback to improve quality of health services is less established.

- The authors analyzed past studies reporting improvement initiatives based on patient experience feedback, identified common barriers to project implementation and developed a model framework to guide future efforts.

- Though evidence on how patient surveys have impacted health services to date lacks rigor, the authors were able to conclude that organizational leaders must first thoroughly understand and explain feedback data to stakeholders clinicians, staff, patients, etc. - before involving all in the development of improvement projects.

\section{Conflicts of interest}

None.

\section{References}

1. Browne K, Roseman D, Shaller D, Edgman-Levitan S. Analysis \& commentary. Measuring patient experience as a strategy for improving primary care. Health Aff (Millwood). 2010;29:921-5. CrossRef

2. Institute of Medicine (U.S.) Committee on Quality of Health Care in America. Crossing the Quality Chasm: A New Health System for the 21st Century. Washington, DC: National Academies Press, 2001.

3. Coulter A. Can patients assess the quality of health care? BMJ. 2006;333(7557):1-2. CrossRef

4. Robert G, Cornwell J. What Matters to Patients? Policy Recommendations - A Report for the Department of Health and NHS Institute for Innovation \& Improvement. Warwick, U.K.: NHS Institute for Innovation \& Improvement, 2011.

5. World Health Organization. The World Health Report 2007. A Safer Future: Global Public Health Security in the 21st Century. Geneva, Switzerland: World Health Organization, 2007.

6. Haugum M, Danielsen K, Iversen HH, Bjertnaes O. The use of data from national and other large-scale user experience surveys in local quality work: a systematic review. Int J Qual Health Care. 2014;26:592-605. CrossRef

7. Crawford MJ, Rutter D, Manley C, et al. Systematic review of involving patients in the planning and development of health care. BMJ. 2002;325(7375):1263. CrossRef

8. Draper M, Cohen P, Buchan H. Seeking consumer views: what use are results of hospital patient satisfaction surveys? Int J Qual Health Care. 2001;13:463-8. CrossRef

9. Richards N, Coulter A. Is the NHS Becoming More PatientCentred? Trends From the National Surveys of NHS Patients in England 2002-07. Oxford, U.K.: Picker Institute Europe, 2007.

10. Gardner K, Mazza D. Quality in general practice - definitions and frameworks. Aust Fam Physician. 2012;41:151-4.

11. Edwards A, Evans R, White P, Elwyn G. Experiencing patient-experience surveys: a qualitative study of the accounts of GPs. Br J Gen Pract. 2011;61:157-66. CrossRef

12. Coulter A, Locock L, Ziebland S, Calabrese J. Collecting data on patient experience is not enough: they must be used to improve care. BMJ. 2014;348:g2225. CrossRef

13. Koch JR, Breland AB, Nash M, Cropsey K. Assessing the utility of consumer surveys for improving the quality of behavioral health care services. J Behav Health Serv Res. 2011;38:234-48. CrossRef

14. Reeves R, Seccombe I. Do patient surveys work? The influence of a national survey programme on local quality-improvement initiatives. Qual Saf Health Care. 2008;17:437-41. CrossRef

15. Boyer L, Francois P, Doutre E, Weil G, Labarere J. Perception and use of the results of patient satisfaction surveys by care providers in a French teaching hospital. Int J Qual Health Care. 2006;18:359-64. CrossRef

16. Davies EA, Materko MM, Charns MP, Seibert ME, Cleary PD. Factors affecting the use of patient survey data for quality improvement in the Veterans Health Administration. BMC Health Serv Res. 2011;11:334. CrossRef 
17. Davies E, Shaller D, Edgman-Levitan S, et al. Evaluating the use of a modified CAHPS survey to support improvements in patient-centred care: lessons from a quality improvement collaborative. Health Expect. 2008;11:160-76. CrossRef

18. Reeves R, West E, Barron D. Facilitated patient experience feedback can improve nursing care: a pilot study for a phase III cluster randomised controlled trial. BMC Health Serv Res. 2013;13:259. CrossRef

19. Davies E, Cleary PD. Hearing the patient's voice? Factors affecting the use of patient survey data in quality improvement. Qual Saf Health Care. 2005;14:428-32. CrossRef

20. Iversen HH, Bjertnaes ØA, Groven G, Bukholm G. Usefulness of a national parent experience survey in quality improvement: views of paediatric department employees. Qual Saf Health Care. 2010;19(5):e38. CrossRef

21. Friedberg MW, SteelFisher GK, Karp M, Schneider EC. Physician groups' use of data from patient experience surveys. J Gen Intern Med. 2011;26:498-504. CrossRef

22. Heje HN, Vedsted P, Olesen F. General practitioners' experience and benefits from patient evaluations. BMC Fam Pract. 2011;12:116. $\underline{\text { CrossRef }}$

23. Zuidgeest M, Strating M, Luijkx K, Westert G, Delnoij D. Using client experiences for quality improvement in long-term care organizations. Int $J$ Qual Health Care. 2012;24:224-9. CrossRef

24. Wensing M, Vingerhoets E, Grol R. Feedback based on patient evaluations: a tool for quality improvement? Patient Educ Couns. 2003;51:149-53. CrossRef
25. Danielsen K, Bjertnaes OA, Garratt A, Forland O, Iversen $\mathrm{HH}$, Hunskaar S. The association between demographic factors, user reported experiences and user satisfaction: results from three casualty clinics in Norway. BMC Fam Pract. 2010;11:73. CrossRef

26. Asprey A, Campbell JL, Newbould J, et al. Challenges to the credibility of patient feedback in primary healthcare settings: a qualitative study. Br J Gen Pract. 2013;63:e200-8. CrossRef

27. Farrington C, Burt J, Boiko O, Campbell J, Roland M. Doctors' engagements with patient experience surveys in primary and secondary care: a qualitative study. Health Expect. 2016 Apr 28 [Epub ahead of print]. CrossRef

28. Brown H, Davidson D, Ellins J. NHS West Midlands Investing for Health Real-Time Patient Feedback Project: Final Report. Birmingham, U.K.: University of Birmingham and NHS West Midlands, 2009.

29. Wiig S, Storm M, Aase K, et al. Investigating the use of patient involvement and patient experience in quality improvement in Norway: rhetoric or reality? BMC Health Serv Res. 2013;13:206. CrossRef

30. Tasa K, Baker GR, Murray M. Using patient feedback for quality improvement. Qual Manag Health Care. 1996;4(2):55-67. CrossRef

(C) 2017 Aurora Health Care, Inc. 